\title{
The Acetate Proton Shuttle between Mutually Trans Ligands
}

\author{
Adiran de Aguirre, ${ }^{\dagger}$ Silvia Díez-González, ${ }^{\dagger}{ }^{\S}$ Feliu Maseras, ${ }^{* \dagger}{ }^{\dagger}$ Marta Martín, ${ }^{\dagger}$ and Eduardo Sola** \\ 'Institute of Chemical Research of Catalonia (ICIQ), The Barcelona Institute of Science and Technology, Av. Països Cata- \\ lans 16, 43007 Tarragona, Spain. \\ ${ }^{\S}$ Department of Chemistry, Imperial College London, Exhibition Road, South Kensington, London SW7 2Az, UK \\ *Instituto de Síntesis Química y Catálisis Homogénea, CSIC - Universidad de Zaragoza, 50009 Zaragoza, Spain.
}

\begin{abstract}
This work addresses a counterintuitive observation in the reactivity of the well-known ruthenium com-

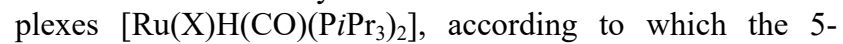
coordinate chloro complex $(\mathrm{X}=\mathrm{Cl}, \mathbf{1})$ is less reactive towards phenylacetylene than its 6-coordinate acetate analogue $(\mathrm{X}=$ $\kappa \mathrm{O}_{2}$-OC(O)Me, $\left.\mathbf{3}\right)$, since 3 undergoes a hydride-to-alkenyl-toalkynyl transformation whereas the reaction of $\mathbf{1}$ stops at the

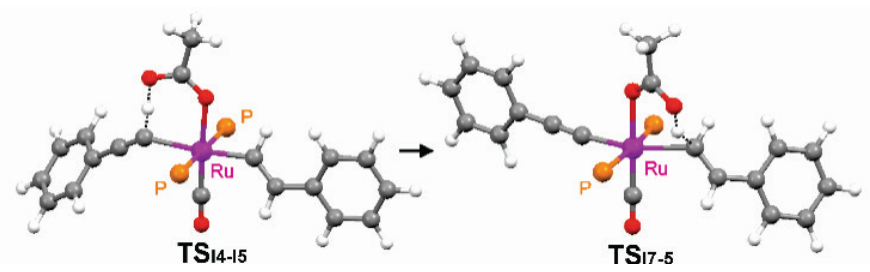
alkenyl derivative. The experimental kinetics of the key alkenyl-to-alkynyl step in the acetate complex are compared to the results of DFT calculations, which disclose the ability of the acetate not only to assist the alkyne $\mathrm{C}-\mathrm{H}$ activation step via a CMD mechanism, but also to subsequently deliver the proton to the alkenyl ligand. Possible consequences of this mechanistic resource connecting mutually trans ligands are briefly discussed on the basis of reported chemoselectivity changes induced by carboxylate ligands in 1-alkyne hydrosilylations catalyzed by this type of ruthenium complexes.
\end{abstract}

\section{INTRODUCTION}

The lone electron pairs in ligands in the first or second coordination sphere often play a role in the activation of $\sigma$ bonds by unsaturated transition metal complexes. ${ }^{1}$ In fact, with the exception of some electron-rich derivatives able to offer at the metal both an empty orbital for reagent coordination and suitable electron density to break bonds via oxidative addition, most complexes must bring into play electrons outside the metal to complete bond cleavages. ${ }^{2}$ Depending on where in the complex these electrons are found, the bond cleavage may receive different mechanistic descriptors. In the particular field of $\mathrm{C}-\mathrm{H}$ bond activations for example, ${ }^{3} 1,2$-additions, $\sigma$-bond metathesis and $\sigma$-CAM ( $\sigma$-coordination-assisted metathesis $)^{4}$ mechanisms utilize electrons formerly in metal-ligand bonds, while the so-called electrophilic substitutions ${ }^{5}$ and the CMD (concerted metalation deprotonation) $^{6}$ or AMLA (ambiphilic metal ligand activation) ${ }^{7}$ alternatives turn on lone pairs in ligands or external bases. All these processes are very similar and resemble bond cleavages accomplished by cooperating Lewis pairs, ${ }^{8}$ the metal being the Lewis acid. ${ }^{9}$

Carboxylates are frequently used as assistant ligands for bond activations, ${ }^{10}$ particularly in $\mathrm{C}-\mathrm{C}$ forming reactions catalyzed by palladium complexes via direct arylation. ${ }^{11}$ While the role of the carboxylate during the $\mathrm{C}-\mathrm{H}$ activation step has been analyzed in depth, ${ }^{12}$ it is commonly assumed that the resulting carboxylic acid merely transfers the proton to a sacrificial base. ${ }^{13}$ Yet, this may not occur if, for instance, the proton returns to the original ligand to cause its tautomerization. Such a process, termed LAPS (ligand-assisted proton shuttle), ${ }^{14}$ has been recognized key in regioselective catalytic hydrations of terminal alkynes via ligand-facilitated vinylidene tautomers. ${ }^{15}$ Besides these possibilities, other destinations for the proton remain still conceivable. In particular, its transfer to a neighboring ligand seems a likely process that might unlock new reaction sequences and trigger more elaborate catalytic transformations.

This work shows that acetate can indeed play such a sophisticated role as functional ligand by offering a lone pair to break $\mathrm{C}-\mathrm{H}$ bonds and subsequently delivering the proton to a neighboring ligand. These observations have been extracted from the behavior of the known ruthenium(II) hydride com-

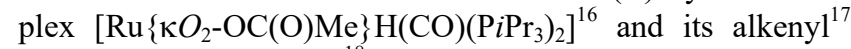
and alkynyl derivatives, ${ }^{18}$ whose acetates drive the exchange of protons between ligands coordinating mutually trans. Such a process overcomes a typical reactivity limitation in octahedral coordination environments, which results from the preferred location of vacant coordination sites trans to strongly $\sigma$ donor ligands such as hydrides or alkenyls. ${ }^{19}$ Accordingly, carboxylate ligands may not only enhance reactivity and change regioselectivity, ${ }^{10,12,14}$ but also modify chemoselectivi$\mathrm{ty}^{20}$

\section{RESULTS AND DISCUSSION}

The five-coordinate chloro complex $\left[\mathrm{Ru}(\mathrm{Cl}) \mathrm{H}(\mathrm{CO})\left({\mathrm{P} i \mathrm{Pr}_{3}}_{3}\right)_{2}\right]$ (1) was reported to form the alkenyl derivative $[\mathrm{Ru}(\mathrm{Cl})(E$ $\left.\mathrm{CH}=\mathrm{CHPh})(\mathrm{CO})\left(\mathrm{PiPr}_{3}\right)_{2}\right](2)$ after insertion of just one equivalent of phenylacetylene (Scheme 1). ${ }^{21}$ In contrast, the sixcoordinate acetate analogue $\left[\mathrm{Ru}\left\{\kappa \mathrm{K}_{2-}\right.\right.$ $\left.\mathrm{OC}(\mathrm{O}) \mathrm{Me}\} \mathrm{H}(\mathrm{CO})\left(\mathrm{P} i \mathrm{Pr}_{3}\right)_{2}\right]$ (3) was observed to further react 
with a second, and even a third equivalent of this reagent. Monitoring of the latter by ${ }^{31} \mathrm{P}$ NMR in toluene- $d_{8}$ solution indicated that formation of alkenyl complex $\left[\mathrm{Ru}\left\{\kappa \mathrm{O}_{2}-\right.\right.$ $\left.\mathrm{OC}(\mathrm{O}) \mathrm{Me}\}(E-\mathrm{CH}=\mathrm{CHPh})(\mathrm{CO})\left(\mathrm{P} i P r_{3}\right)_{2}\right](4)$ and its consumption to form alkynyl derivative $\left[\mathrm{Ru}\left\{\kappa \mathrm{O}_{2^{-}}\right.\right.$

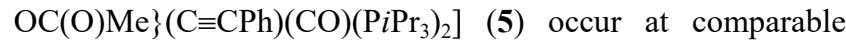
rates. As detailed in Figure 1, the kinetic features of the transformation of $\mathbf{4}$ into $\mathbf{5}$ are consistent with the expected second order reaction between the alkenyl precursor and the alkyne.

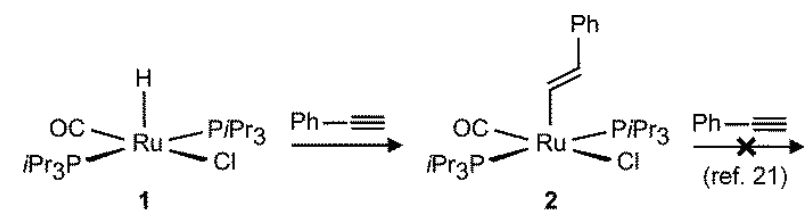

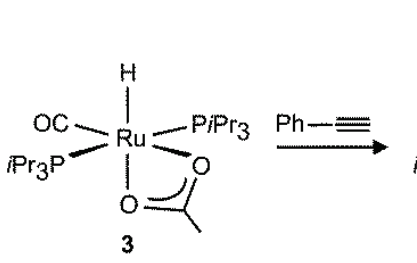

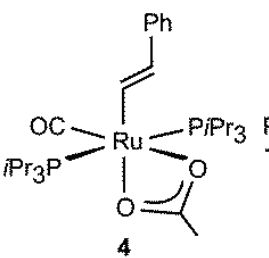<smiles>C#CP</smiles>

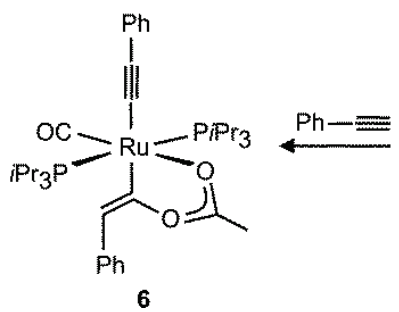

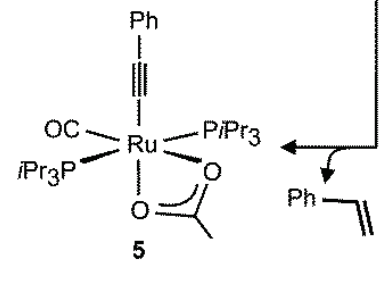

Scheme 1

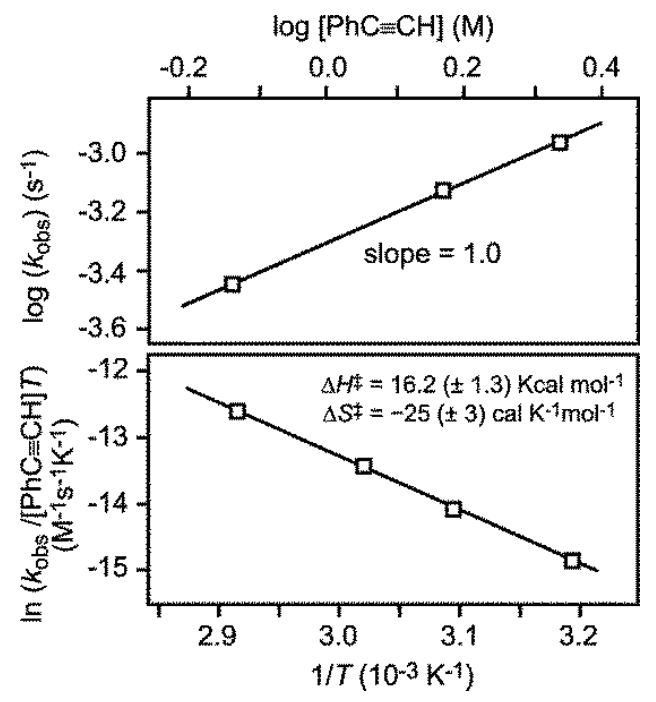

Figure 1. (above) Dependence upon phenylacetylene concentration of the experimental pseudo first-order rate constants $\left(k_{\mathrm{obs}}\right)$ for the transformation of $\mathbf{4}$ into $\mathbf{5}$. (below) Eyring analysis of the second-order rate constants.

The subsequent transformation of $\mathbf{5}$ into the alkenyl ester complex $\mathbf{6}$ was found to be slow, taking several days at room temperature. All complexes in Scheme 1 had been previously reported, ${ }^{16-18}$ although 4-6 were synthesized by procedures other than the present reaction sequence. This hydride $\rightarrow$ alkenyl $\rightarrow$ alkynyl sequence is quite common in the chemistry of ruthenium and frequently ends in butenynyl complexes formed after the coupling of two alkyne moieties. ${ }^{22,23}$ Actually, this is the case for the analogue of 2 bearing $\mathrm{PPh}_{3}$ instead of $\mathrm{PiPr}_{3}$ ligands, which was found to form a five-coordinate butenynyl derivative under forcing reaction conditions. ${ }^{24}$ Complex 2, however, did not undergo reaction even in the presence of excess alkyne at high temperatures.

To rationalize the counterintuitive reactivity difference between 2 and 4, their reactions with phenylacetylene were studied by DFT methods. Initially, we computed a series of free energy profiles on model complexes with $\mathrm{PMe}_{3}$ as phosphine (calculations labeled with the sufix m) to explore different mechanistic scenarios. After, we calculated the most likely option with the experimental $\mathrm{P} \mathrm{Pr}_{3}$ system, for a straightforward comparison with the obtained kinetic data. Some of the computed profiles are presented here, while others are included as Supporting Information.

The insertion of phenylacetylene into the $\mathrm{Ru}-\mathrm{H}$ bond of this type of complexes has been previously calculated and discussed by Eisenstein, Caulton and co-workers. ${ }^{25}$ As detailed for $1 \mathbf{m}$ in Figure 2, the reaction is feasible after distortion of the square-pyramidal ground-state geometry of the complex to allow the incoming alkyne coordinate cis to the hydride. The most favorable option is opening the vacancy trans to $\mathrm{CO}$ to attain intermediate $\mathbf{I 1 m}$. Then, the alkyne would insert smoothly into the $\mathrm{Ru}-\mathrm{H}$ bond, resulting in alkenyl complex $2 \mathrm{~m}, 24.5 \mathrm{kcal} \mathrm{mol}^{-1}$ below the reactants. The calculated profile in Figure 2 continues with the non-observed alkenyl-toalkynyl metathesis step in $\mathbf{2} \mathbf{m}$, which would be exergonic by $11.7 \mathrm{kcal} \mathrm{mol}^{-1}$, but would require a hardly attainable activation barrier of at least $27.3 \mathrm{kcal} \mathrm{mol}^{-1}$, probably higher for the more sterically encumbered real complex 2 .

The profile for the model acetate complex $\mathbf{3 m}$ in this mechanistic scenario based on distortions of the complexes groundstate geometries, is qualitatively similar to that of the chloro analogue, although activation barriers increase by about 6 to 8 kcal $\mathrm{mol}^{-1}$ because of the extra oxygen atom coordination to the sixth position of the stable complexes. The initial phenylacetylene insertion has an overall activation barrier of $16.2 \mathrm{kcal}$ $\mathrm{mol}^{-1}$, the highest point corresponding to the first transition state $\mathbf{T S}_{3 \mathrm{~m}-\mathbf{I 3 m}}$. This value still corresponds to a reaction possible at room temperature. On the contrary, the calculated barrier for the (experimentally observed) alkenyl-to-alkynyl step is as high as $34.0 \mathrm{kcal} \mathrm{mol}^{-1}$ from intermediate $\mathbf{4 m}$ to transition state $\mathbf{T S}_{\mathbf{I} 4}, \mathbf{m}-5 \mathrm{~m}$.

An alternative evolution of $\mathbf{4}$ based on the possible assistance of the acetate in the activation of the second molecule of phenylacetylene was hence explored. As a result, we found not only the expected facile alkyne $\mathrm{C}-\mathrm{H}$ activation via concerted metalation deprotonation (CMD), ${ }^{12}$ but also a feasible pathway for the subsequent transfer of the proton to the alkenyl ligand, forming styrene and the alkynyl complex 5. This transfer is formally similar to previously reported examples of ligandassisted proton shuttle (LAPS), ${ }^{14,15}$ although in this case the shuttle connects different ligands instead of different carbons of the same ligand. The structures and free energies calculated for this new reaction sequence in the real $\mathrm{P} \mathrm{Pr}_{3}$ system are summarized in Figure 3. A further key difference between this mechanism and that in Figure 2 is the initial alkyne coordination, which can now take place at the most readily accessible position of $\mathbf{4}$, trans to the alkene ligand. 


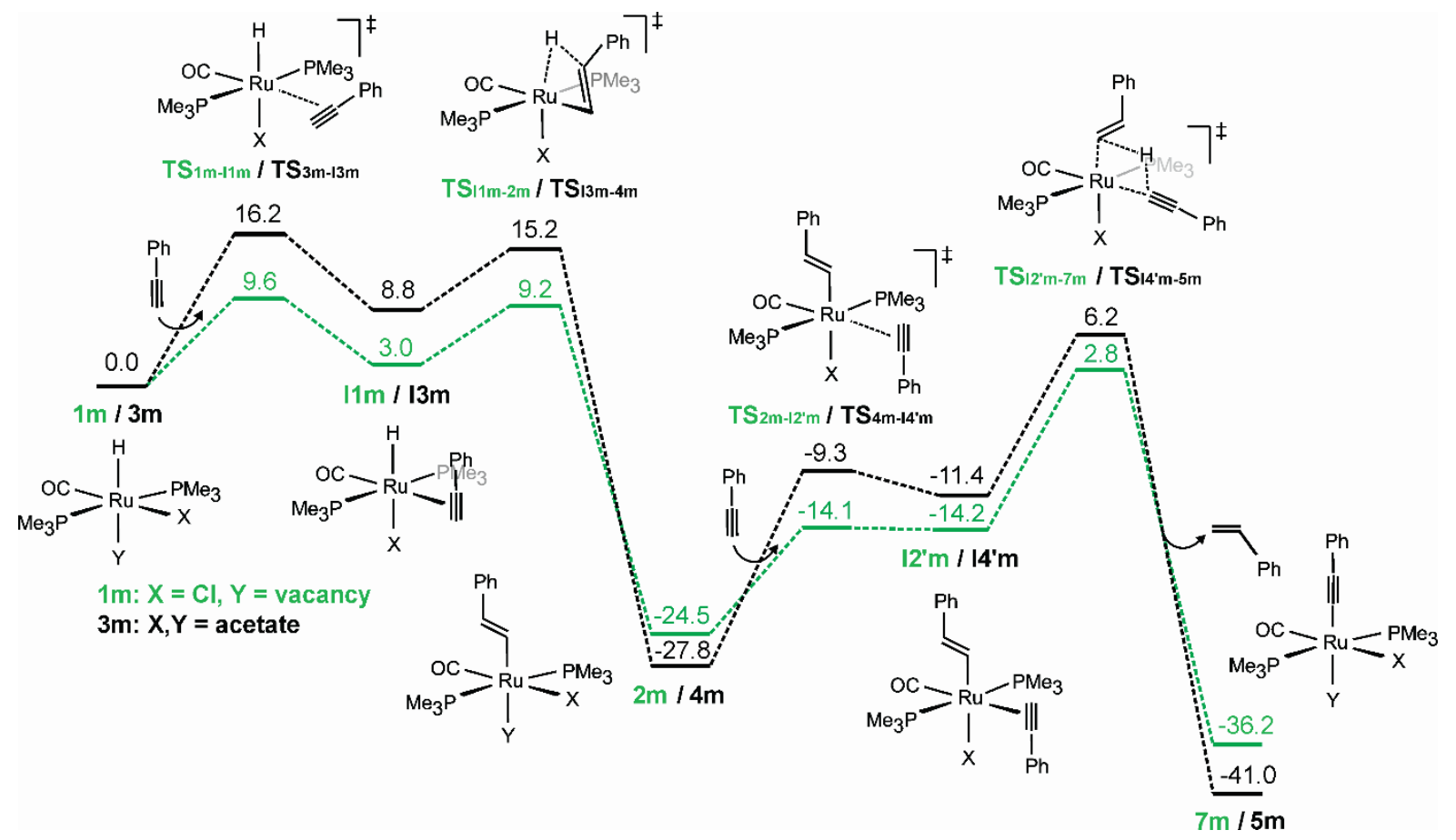

Figure 2. Free energy profiles (in kcal mol ${ }^{-1}$ ) for the hydride-to-alkenyl-to-alkynyl sequence in $\mathrm{PMe}_{3}$ models of 5-coordinate chloro complex $\mathbf{1 m}$ (green) and 6-coordinated acetate complex 3m (black), through a direct mechanism that generates vacant sites cis to hydride and alkenyl ligands.

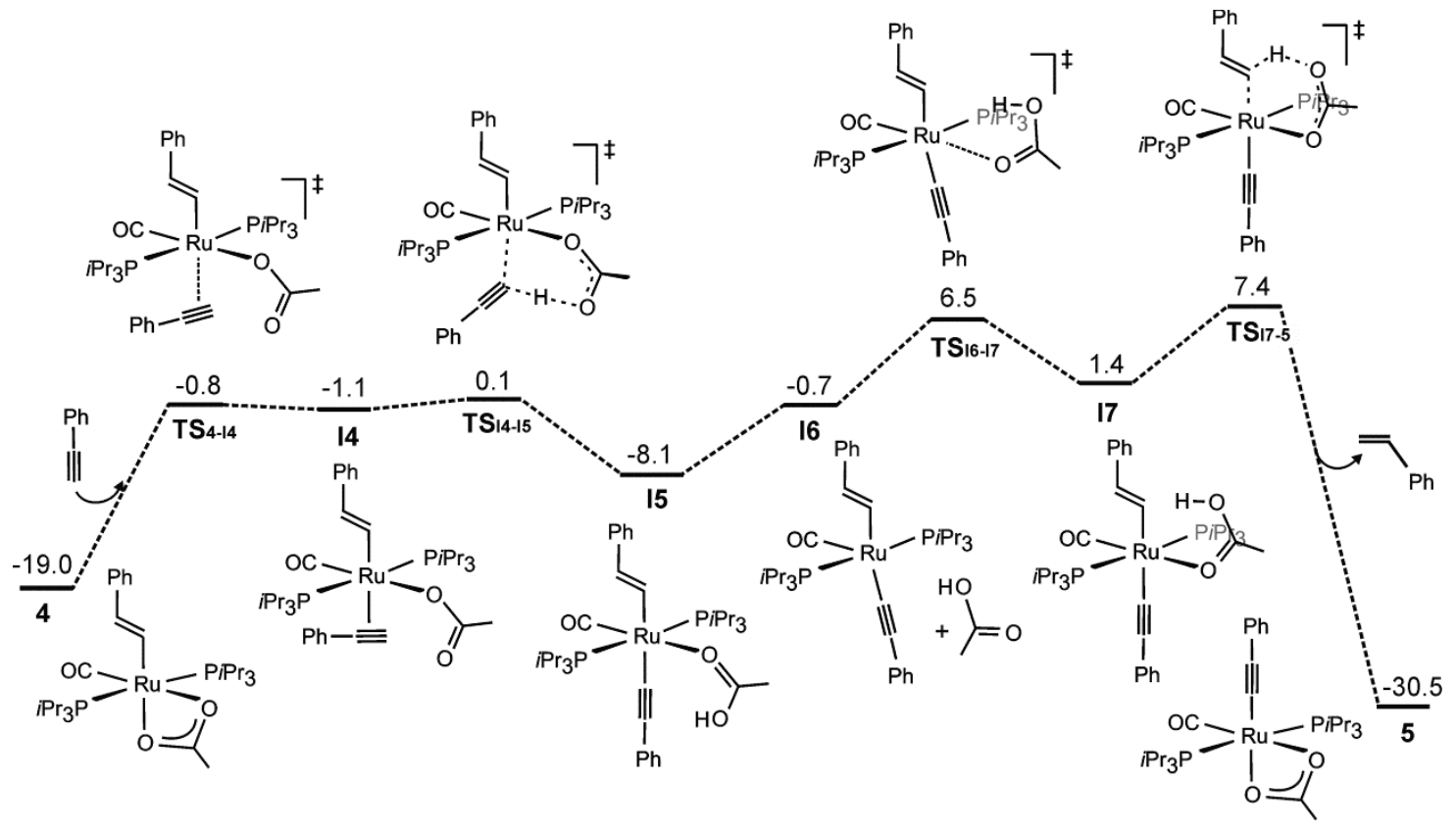

Figure 3. Free energy profile (in $\mathrm{kcal} \mathrm{mol}^{-1}$ ) for the alkenyl-to-alkynyl transformation in 4, through a mechanism featuring $\mathrm{C}$-H activation (CMD) and proton shuttle (LAPS) steps assisted by the acetate ligand. Energy relative to the precursor hydride complex 3.

The energy profile of Figure 3 features two high lying transition states, $\mathbf{T} \mathbf{S}_{\mathbf{I 6 - 1 7}}$ and $\mathbf{T} \mathbf{S}_{\mathbf{1 7 - 5}}$, with similar barriers (from $\mathbf{4}$ ) of 25.5 and $26.4 \mathrm{kcal} \mathrm{mol}^{-1}$, respectively. Both barriers are only slightly above the experimental estimation: $23.7( \pm 2.1) \mathrm{kcal}$ $\mathrm{mol}^{-1}$, thus being good candidates for the rate-limiting step. Decomposition of free energies in enthalpic and entropic terms suggests that both TS are equally compatible with experiment.
Experimental activation parameters are $\Delta H^{*}=16.2( \pm 1.3) \mathrm{kcal}$ $\mathrm{mol}^{-1}$ and $T \Delta S^{\ddagger}=7.1( \pm 0.8) \mathrm{kcal} \mathrm{mol}^{-1}$, while the respective calculated values are 12.0 and $13.6 \mathrm{kcal} \mathrm{mol}^{-1}$ for $\mathbf{T S}_{\mathbf{I 6 - 1 7}}$, and 12.8 and $13.6 \mathrm{kcal} \mathrm{mol}^{-1}$ for $\mathbf{T S}_{\mathbf{1 7 - 5}}$. Clearly, entropic effects are overestimated in the calculation, but the signs of the contributions are correct. A further piece of evidence coming from 
experiment is the kinetic isotopic effect observed using $\mathrm{PhC} \equiv \mathrm{CD}$ as reagent: $k_{\mathrm{obsH}} / k_{\mathrm{obsD}}=1.6$. The value seems too close to 1 for a rate-limiting $\mathrm{C}-\mathrm{H}$ or $\mathrm{O}-\mathrm{H}$ bond breaking step, ${ }^{12,26}$ thus discarding $\mathbf{T S}_{\mathbf{I 4 - 1 5}}$ and $\mathbf{T} \mathbf{S}_{\mathbf{I 7 - 5}}$, especially after confirming that their geometries are not particularly early. ${ }^{27}$ Accordingly, the KIE points to $\mathbf{T S}_{\mathbf{I 6 - 1 7}}$ as the highest energy point of the mechanism.

This $\mathbf{T S}_{\mathbf{I 6 - 1 7}}$, associated to the return of the acetic acid to the ruthenium coordination sphere, constitutes the only qualitative discrepancy between the reaction profile obtained from the real system and that derived from the $\mathrm{PMe}_{3}$ model. In the latter (Figure $\mathrm{S} 1$ ), the acetic acid fragment of intermediate $\mathbf{I 5 m}$ can rotate around the $\mathrm{Ru}-\mathrm{O}$ bond to bring the proton close to the alkenyl group, whereas this is not feasible in the real intermediate $\mathbf{I 5}$ because of steric reasons. Alternative mechanisms where the acetate "slips" in the metal coordination sphere without rotation were explored without success. Instead, it is better for the acetic acid to separate from ruthenium and return with the proper orientation in I7. Calculations in the $\mathrm{PMe}_{3}$ model produced an overall activation barrier much lower than the experimental $\left(19.9 \mathrm{kcal} \mathrm{mol}^{-1}\right)$, while calculated structures close to the TS for acetic acid rotation seemed sterically crowded and likely sensitive to the phosphine size. The steric properties of the real $\mathrm{P}_{2} \mathrm{Pr}_{3}$ system were also found to increase the calculated free energy barrier for the first alkyne insertion in 3 to form 4, up to $23.2 \mathrm{kcal} \mathrm{mol}^{-1}$ (Figure S2), although the shape of the energy profile does not change with respect to that in Figure 2. We also explored the possible occurrence of the CMD/LAPS sequence in complex 2 (Figure S3). The barrier is prohibitively high $\left(34.8 \mathrm{kcal} \mathrm{mol}^{-1}\right)$ because the chloride ligand is much less basic than acetate, and thus less efficient as proton acceptor.

Viewed as a mere hydrogen transfer, the overall process of Figure 3 has several well-characterized precedents in solvent-, counteranion-, and ligand-assisted tautomerizations and related reactions. ${ }^{14,15,28}$ However, when considering that the origin and destination of the hydrogen atom are two trans ligands, the case emerges as a simple paradigm to circumvent the ubiquitous energy-consuming distortions required to accommodate reactive ligands in relative cis positions of catalytically active complexes. Consequences of this extra mechanistic resource of the acetate can be inferred from the reported catalytic behavior of this type of complexes in 1-alkyne hydrosilylations. $^{29,30}$ The replacement of chloride by acetate in $\left[\mathrm{Ru}(\mathrm{X}) \mathrm{H}(\mathrm{CO})\left(\mathrm{PPh}_{3}\right)_{\mathrm{n}}\right]$ catalyst precursors was observed to change the chemoselectivity in the addition of triethylsilane to phenylacetylene, favoring products of dehydrogenative silylation ( $\mathrm{PhC} \equiv \mathrm{CSiEt}_{3}$ and styrene) over those of hydrosilylation (Z- and $E$-alkenylsilanes). ${ }^{20}$ Such a selectivity change is an expected result of ease alkenyl-to-alkynyl metathesis, since the reaction produces styrene together with alkynyl complexes: proposed key intermediates in dehydrogenative silylations. ${ }^{31}$ In agreement with this, we have confirmed (by ${ }^{1} \mathrm{H}$ and ${ }^{31} \mathrm{P}$ NMR) that both alkenyl 4 and alkynyl 5 react with excess triethylsilane to regenerate hydride $\mathbf{3}$, thus closing competing catalytic cycles for phenylacetylene hydrosilylation and dehydrogenative silylation, respectively.

\section{CONCLUSION}

Our results show that acetate ligands can not only assist $\mathrm{C}-\mathrm{H}$ bond activations at adjacent metal coordination positions but also subsequently deliver the $\mathrm{H}$ atom to other neighboring ligands. In particular, this can enable reactions between ligands mutually trans to each other, not feasible through conventional concerted elementary steps. This additional resource can expand the reactivity of complexes and modify their catalytic performance.

\section{EXPERIMENTAL SECTION}

All manipulations were carried out with exclusion of air by using standard Schlenk techniques. Solvents were obtained from a solvent purification system (MBraun). Deuterated solvents were dried with appropriate drying agents and degassed with argon prior to use. NMR spectra were recorded on a Bruker Avance $300 \mathrm{MHz}$ spectrometer. GC-MS analysis was carried out in an Agilent 6890 Series GC System, equipped with an Agilent 5973 Network Mass Selective Detector, using a crosslinked methyl silicone gum capillary column.

Complex 4 was prepared from 2 and sodium acetate, as detailed in reference 17. Complex 5 was prepared by treatment of 4 (191 mg, $0.31 \mathrm{mmol})$ with phenylacetylene $(73 \mu \mathrm{L}, 0.66 \mathrm{mmol})$ in $5 \mathrm{~mL}$ of toluene. After $4 \mathrm{~h}$ of reaction at $353 \mathrm{~K}$, the solution was taken to dryness and the residue was treated with cool hexane, decanted, and dried in vacuo (yield $152 \mathrm{mg}, 80 \%$ ). The ${ }^{1} \mathrm{H},{ }^{31} \mathrm{P}\left\{{ }^{1} \mathrm{H}\right\}$ and ${ }^{13} \mathrm{C}\left\{{ }^{1} \mathrm{H}\right\}$ NMR spectra of the resulting yellow solid matched those previously reported for 5 in reference 18. The reaction between $\mathbf{4}$ and triethylsilane excess in toluene- $d_{8}$ at room temperature was observed by ${ }^{1} \mathrm{H}$ and ${ }^{31} \mathrm{P}$ NMR to cleanly produce the $E$-alkenylsilane and complex 3, though this outcome slowly evolved into other unidentified products. Similarly, complex $\mathbf{5}$ and triethylsilane excess reacted to initially form 3 (NMR) and $\mathrm{PhC} \equiv \mathrm{CSiEt}_{3}(\mathrm{GC}-\mathrm{MS})$, though these products readily disappeared to form an intricate mixture of several other products.

Kinetics: The reactions of $\mathbf{4}$ with phenylacetylene excess were followed by monitoring the decrease in the intensity of the ${ }^{31} \mathrm{P}\left\{{ }^{1} \mathrm{H}\right\}$ NMR signal of 4 in toluene- $d_{8}$ solution. Samples were prepared from aliquots of a 4.14 E-2 M common solution of 4 in this solvent. After addition of the corresponding phenylacetylene excess, sample volumes were adjusted to $0.5 \mathrm{~mL}$. $k_{\text {obs }}$ values (Table 1 ) were obtained from exponential fittings of the intensity vs. time data. Errors in the magnitudes obtained from the Eyring regressions were estimated through conventional error propagation formulas, ${ }^{32}$ assuming $1 \mathrm{~K}$ error in the temperature and a $10 \%$ error in the rate constant.

Computational Details: All calculations were carried out using the Gaussian09 (Rev.D01) package. ${ }^{33}$ The $\omega$ B97x-D level of theory was used for all calculations. ${ }^{34}$ All the structures were optimized in solution (toluene: $\varepsilon=2.3741$ ), using the SMD implicit solvation model. ${ }^{35}$ Vibrational frequency calculations for all stationary points were carried out in order to assign their nature as minima (zero imaginary frequencies) or as transition state (one imaginary frequency). 6$31+\mathrm{G}(\mathrm{d})$ basis set ${ }^{36}$ for $\mathrm{H}, \mathrm{C}, \mathrm{P}, \mathrm{O}$ and $\mathrm{Cl}$ atoms and $\mathrm{SDD}$ for $\mathrm{Ru}$ atom and its corresponding pseudopotential ${ }^{37}$ were used for optimizations and frequency calculations. For the real system ( $\mathrm{P} \mathrm{Pr}_{3}$ ligand), potential energies were further refined through single point calculations in solution using the $6-311++\mathrm{G}(\mathrm{d}, \mathrm{p})$ basis $\operatorname{set}^{38}$ for $\mathrm{H}, \mathrm{C}, \mathrm{P}, \mathrm{O}$ and $\mathrm{Cl}$ atoms. All the reported energies are free energies in solution at $298 \mathrm{~K}$ and $1 \mathrm{~atm}$. The accurate calculation of free energies of reaction in solution is still a topic of discussion, ${ }^{39,40}$ and a number of refinements have been proposed, some including scaling factors for specific functionals. ${ }^{41}$ The issue is not critical for the interpretation of the results in the current manuscript. A dataset collection of all computational data is available in the ioChem-BD repository. ${ }^{42}$ 
Table 1. Experimental kinetic data for the reactions of complex 4 with phenylacetylene.

\begin{tabular}{llll}
\hline$T(\mathrm{~K})$ & {$[\mathrm{PhC} \equiv \mathrm{CH}](\mathrm{M})$} & $k_{\mathrm{obs}}\left(\mathrm{s}^{-1}\right)$ & $k_{\mathrm{obs}} /[\mathrm{PhC} \equiv \mathrm{CH}]\left(\mathrm{M}^{-1} \mathrm{~s}^{-1}\right)$ \\
\hline 313 & 1.48 & $1.64 \mathrm{E}-4$ & $1.11 \mathrm{E}-4$ \\
323 & 1.48 & $3.71 \mathrm{E}-4$ & $2.51 \mathrm{E}-4$ \\
323 & $1.48(\mathrm{PhC} \equiv \mathrm{CD})$ & $2.36 \mathrm{E}-4$ & \\
331 & 0.73 & $3.56 \mathrm{E}-4$ & \\
331 & 1.48 & $7.43 \mathrm{E}-4$ & $5.02 \mathrm{E}-4$ \\
331 & 2.19 & $1.09 \mathrm{E}-3$ & \\
343 & 1.48 & $1.72 \mathrm{E}-3$ & $1.16 \mathrm{E}-3$ \\
\hline
\end{tabular}

\section{ASSOCIATED CONTENT}

\section{Supporting Information}

A set of additional free energy profiles and the corresponding discussion, plus a text file of all computed Cartesian coordinates (XYZ file).The Supporting Information is available free of charge on the ACS Publications website.

\section{AUTHOR INFORMATION}

\section{Corresponding Authors}

*fmaseras@iciq.es

*sola@unizar.es

\section{ORCID}

Adiran de Aguirre: 0000-0001-7991-6404

Silvia Díez-González: 0000-0003-3950-5156

Feliu Maseras: 0000-0001-8806-2019

Marta Martín: 0000-0001-7819-670X

Eduardo Sola: 0000-0001-5462-6189

Notes

The authors declare no competing financial interest.

\section{ACKNOWLEDGMENT}

The authors would like to dedicate this work to Professor Ernesto Carmona on the occasion of his $70^{\text {th }}$ birthday.

The authors are thankful for financial support from Ministerio de Economía, Industria y Competitividad (MINECO) / Fondo Europeo de Desarrollo Regional (FEDER) (Grants CTQ2015-64486$\mathrm{R}$ and CTQ2017-87792-R), MINECO-Severo Ochoa Excellence Accreditation 2014-2018 (Grant SEV-2013-0319) and Gobierno de Aragón / FEDER (E08_17R). A. de A. thanks MINECO for a FPI fellowship (BES-2015-073012).

\section{REFERENCES}

(1) Bercaw, J. E.; Labinger, J. A. The Coordination Chemistry of Saturated Molecules. Proc. Natl. Acad. Sci. USA 2007, 104, 6899-6900 and references therein.

(2) For a discussion and leading references in the case of $\mathrm{C}-\mathrm{H}$ bonds, see: Ess, D. H.; Gunnoe, B. T.; Cundari, T. R.; Goddard III, W. A.; Periana, R. A. Ligand Lone-Pair Influence on Hydrocarbon $\mathrm{C}-\mathrm{H}$ Activation: A Computational Perspective. Organometallics 2010, 29, 6801-6815.

(3) (a) Lersch, M.; Tilset, M. Mechanistic Aspects of C-H Activation by Pt Complexes. Chem. Rev. 2005, 105, 2471-2526. (b) Balcells, D.; Clot, E.; Eisenstein, O. C-H Bond Activation in Transition Metal Species from a Computational Perspective. Chem. Rev. 2010, 110, 749-823.
(4) Perutz, R. N.; Sabo-Etienne, S. The $\sigma$-CAM Mechanism: $\sigma$ Complexes as the Basis of $\sigma$-Bond Metathesis at LateTransition-Metal Centers. Angew. Chem., Int. Ed. 2007, 46, $2578-2592$.

(5) Oxgaard, J.; Tenn, W. J. III; Nielsen, R. J.; Periana, R. A.; Goddard, W. A. III Mechanistic Analysis of Iridium Heteroatom $\mathrm{C}-\mathrm{H}$ Activation: Evidence for an Internal Electrophilic Substitution Mechanism. Organometallics 2007, 26, $1565-1567$

(6) Lapointe, D.; Fagnou, K. Overview of the Mechanistic Work on the Concerted Metallation-Deprotonation Pathway. Chem. Lett. 2010, 39, 1118-1126.

(7) Boutadla, Y.; Davies, D. L.; Macgregor, S. A.; PobladorBahamonde, A. I. Computational and Synthetic Studies on the Cyclometallation Reaction of Dimethylbenzylamine with $\left[\mathrm{IrCl}_{2} \mathrm{Cp}^{*}\right]_{2}$ : Role of the Chelating Base. Dalton Trans., 2009, 5887-5893.

(8) Stephan, D. W.; Erker, G. Frustrated Lewis Pairs: Metal-free Hydrogen Activation and More. Angew. Chem., Int. Ed. 2010, 49, 46-76

(9) Flynn, S. R.; Wass, D. F. Transition Metal Frustrated Lewis Pairs. ACS Catalysis 2013, 3, 2574-2581.

(10) (a) Ackermann, L. Carboxylate-Assisted Transition-MetalCatalyzed $\mathrm{C}-\mathrm{H}$ Bond Functionalizations: Mechanism and Scope. Chem. Rev. 2011, 111, 1315-1345. (b) Ackermann, L. Carboxylate-Assisted Ruthenium-Catalyzed Alkyne Annulations by $\mathrm{C}-\mathrm{H} / \mathrm{Het}-\mathrm{H}$ Bond Functionalizations. Acc. Chem. Res. 2014, 47, 281-295.

(11) (a) Cho, S.-H.; Kim, J. Y.; Kwak, J.; Chang, S. Recent Advances in the Transition Metal-Catalyzed Twofold Oxidative $\mathrm{C}-\mathrm{H}$ Bond Activation Strategy for $\mathrm{C}-\mathrm{C}$ and $\mathrm{C}-\mathrm{N}$ Bond Formation. Chem. Soc. Rev. 2011, 40, 5068-5083. (b) Lyons, T. W.; Sanford, M. S. Palladium-Catalyzed Ligand-Directed C-H Functionalization Reactions. Chem. Rev. 2010, 110, 1147-1169. (c) Chiusoli, G. P.; Catellani, M.; Costa, M.; Motti, E.; Della Ca', N.; Maestri, G. Catalytic $\mathrm{C}-\mathrm{C}$ Coupling through $\mathrm{C}-\mathrm{H}$ Arylation of Arenes or Heteroarenes. Coord. Chem. Rev. 2010, 254, 456-469. (d) Sun, C.-L.; Li, B.-J. Shi, Z.-J. PdCatalyzed Oxidative Coupling with Organometallic Reagents via $\mathrm{C}-\mathrm{H}$ Activation. Chem. Commun. 2010, 46, 677-685. (e) Alberico, D.; Scott, M. E.; Lautens, M. Aryl-Aryl Bond Formation by Transition-Metal-Catalyzed Direct Arylation. Chem. Rev. 2007, 107, 174-238. (f) Satoh, T.; Miura, M. Catalytic Direct Arylation of Heteroaromatic Compounds. Chem. Lett. 2007, 36, 200-205.

(12) Davies, D. L.; MacGregor, S. A.; McMullin, C. L. Computational Studies of Carboxylate-Assisted C-H Activation and Functionalization at Group 8-10 Transition Metal Centers. Chem. Rev. 2017, 117, 8649-8709.

(13) Lafrance, M.; Fagnou, K. Palladium-Catalyzed Benzene Arylation: Incorporation of Catalytic Pivalic Acid as a Proton Shuttle and a Key Element in Catalyst Design. J. Am. Chem. Soc. 2006, 128, 16496-16497.

(14) Johnson, D. G.; Lynam, J. M.; Slattery, J. M. Welby, C. E. Insights into the Intramolecular Acetate-Mediated Formation of Ruthenium Vinylidene Complexes: A Ligand-Assisted Proton Shuttle (LAPS) Mechanism. Dalton Trans. 2010, 39, 10432-10441.

(15) Breit, B.; Gellrich, U.; Li, T.; Lynam, J. M.; Milner, L. M.; Pridmore, N.; Slattery, J. M.; Whitwood, C. Mechanistic Insight into the Ruthenium-Catalysed Anti-Markovnikov Hydration of Alkynes Using a Self-Assembled Complex: A Crucial Role for Ligand-Assisted Proton Shuttle Processes. Dalton Trans. 2014, 43, 11277-11285.

(16) Esteruelas, M. A.; Werner, H. Five- and Six-Coordinate Hydrido(carbonyl)-Ruthenium(II) and -Osmium(II) Complexes Containing Triisopropylphosphine as Ligand. J. Organomet. Chem. 1986, 303, 221-231.

(17) Werner, H.; Esteruelas, M. A.; Otto, H. Insertion Reactions of the 16-Electron Complexes $\mathrm{MHCl}(\mathrm{CO})\left(\mathrm{P}-\mathrm{i}-\mathrm{Pr}_{3}\right),(\mathrm{M}=\mathrm{Ru}, \mathrm{Os})$ 
with Alkynes. The X-ray Crystal Structure of Os((E)$\mathrm{CH}=\mathrm{CHPh}) \mathrm{CI}(\mathrm{CO})\left(\mathrm{P}-i-\mathrm{Pr}_{3}\right)_{2} . \quad$ Organometallics 1986, 5 , 2295-2299.

(18) Esteruelas, M. A.; Lahoz, F. J.; López, A. M.; Oñate, E.; Oro, L. A. Addition of $\mathrm{CH}_{3} \mathrm{CO}_{2} \mathrm{H}$ and $\mathrm{HBF}_{4}$ to Alkynyl Complexes of Ruthenium(II) and Osmium(II). Organometallics 1994, 13, 1669-1678.

(19) For a discussion, see: Sola, E.; García-Camprubí, A.; Andrés, J. L.; Martín, M.; Plou, P. Iridium Compounds with $\kappa-P, P, S i$ (biPSi) Pincer Ligands: Favoring Reactive Structures in Unsaturated Complexes. J. Am. Chem. Soc. 2010, 132, 9111-9121.

(20) Martin, M.; Sola, E.; Lahoz, F. J.; Oro, L. A. Trans Additions of Silanes to 1-Alkynes Catalyzed by Ruthenium Complexes: Role of in Situ Formed Polynuclear Aggregates. Organometallics 2002, 21, 4027-4029.

(21) Esteruelas, M. A.; Herrero, L. A.; Oro, L. A. Exclusive Formation of cis- $\mathrm{PhCH}=\mathrm{CH}\left(\mathrm{SiEt}_{3}\right)$ by Addition of $\mathrm{HSiEt}_{3}$ to

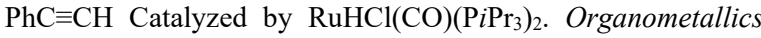
1993, 12, 2377-2379.

(22) For complexes closely related to those in Scheme 1, see: (a) Deshpande, S. S.; Gopinathan, S.; Gopinathan, C. J. Insertion Reactions of Acetylenes with Hydridoruthenium(II) Carboxylates. Organomet. Chem. 1991, 415, 263-270. (b) El Guaouzi, M.; Yáñez, R.; Ros, J.; Alvarez-Larena, A.; Piniella, J. F. The Formation of $\sigma$-Phenylethynyl and $\sigma$-Diphenylbutenynyl Complexes in the Reaction of $\sigma$-Alkenyl Ruthenium(II) Complexes with Phenylacetylene. The X-Ray Structure of a Ruthenium(II) Complex Containing a $\sigma$-Phenylethynyl Ligand. Inorg. Chem. Commun. 1999, 2, 288-291. (c) Bedford, R. B.; Cazin, C. S. J. Alkyne Insertion Reactions of $\left[\mathrm{RuH}\left(\kappa^{2}-\mathrm{S}_{2} \mathrm{CNEt}_{2}\right)(\mathrm{CO})\left(\mathrm{PPh}_{3}\right)_{2}\right]$ : Synthesis of Alkenyl, Alkynyl and Enynyl Complexes. J. Organomet. Chem. 2000, 598, 20-23. (d) Patel, P.; Naeem, S.; White, A.J. P.; Wilton-Ely, J. D. E. T. Synthesis and Reactivity of Dialkyldithiophosphate Complexes of Ruthenium(II). RSC Advances 2012, 2, 999-1008.

(23) For examples in other ruthenium systems: (a) Echavarren, A. M.; López, J.; Santos, A.; Romero, A.; Hermoso, J. A.; Vegas, A. Reactions of Cationic Ruthenium Hydrides with 1-Alkynes: Formation of a-Alkynylruthenium Complexes and Reduction of 1-Alkynes to 1-Alkenes. Organometallics 1991, 10, 2371-2376. (b) Santos, A.; López, J.; Montoya, J.; Noheda, P.; Romero, A.; Echavarren, A. M. Synthesis of New Ruthenium(II) Carbonyl Hydrido, Alkenyl, and Alkynyl Complexes with Chelating Diphosphines. Organometallics 1994, 13, 3605-3615. (c) Santos, A.; López, J.; Galán, A.; González, J. J.; Tinoco, P.; Echavarren, A. The Effect of N-Donor Ligands on the Reaction of Ruthenium Hydrides with 1-Alkynes. Organometallics 1997, 16, 3482-3488. (d) Basseti, M.; Marini, S.; Tortorella, F.; Cadierno, V.; Díez, J.; Gamasa, M. P.; Gimeno, J. Dimerization of Terminal Alkynes Catalyzed by Indenyl Ruthenium(II) Complexes. J. Organomet. Chem. 2000, 593594, 292-298.

(24) Santos, A.; López, J.; Matas, L.; Ros, J.; Galán, A.; Echavarren, A. M. Synthesis of Butenynylruthenium Complexes from Hydrido, Alkenyl, or Alkynyl Complexes. Organometallics 1993, $12,4215-4218$.

(25) Marchenko, A. V.; Gérard, H.; Eisenstein, O.; Caulton, K. G. A Comprehensive View of $\mathrm{M}-\mathrm{H}$ Addition Across the $\mathrm{RC} \equiv \mathrm{CH}$ Bond: Frustration Culminating in Ultimate Union. New J. Chem. 2001, 25, 1244-1255.

(26) Gómez-Gallego, M.; Sierra, M. A. Kinetic Isotope Effects in the Study of Organometallic Reaction Mechanisms. Chem. Rev. 2011, 11, 4857-4963.

(27) Algarra, A. G.; Cross, W. B.; Davies, D. L.; Khamker, Q.; Macgregor, S. A.; McMullin, C. L.; Singh, K. Combined Experimental and Computational Investigations of Rhodium- and Ruthenium-Catalyzed $\mathrm{C}-\mathrm{H}$ Functionalization of Pyrazoles with Alkynes. J. Org. Chem. 2014, 79, 1954-1970.
(28) For examples and leading references, see: (a) Kovács, G.; Ujaque, G.; Lledós, A. The Reaction Mechanism of the Hydroamination of Alkenes Catalyzed by Gold(I)-Phosphine: The Role of the Counterion and the N-Nucleophile Substituents in the Proton-Transfer Step. J. Am. Chem. Soc. 2008, 130, 853-864. (b) Jiménez-Tenorio, M.; Puerta, M. C.; Valerga, P.; Ortuño, M. A.; Ujaque, G.; Lledós, A. Counteranion and Solvent Assistance in Ruthenium-Mediated Alkyne to Vinylidene Isomerizations. Inorg. Chem. 2013, 52, 8919-8932. (c) Cong, X.; Tang, H.; Wu, C.; Zeng, X. Role of Mono-N-protected Amino Acid Ligands in Palladium(II)-Catalyzed Dehydrogenative Heck Reactions of Electron-Deficient (Hetero)arenes: Experimental and Computational Studies. Organometallics 2013, 32, 6565-6575. (d) Arita, A. J.; Cantada, J.; Grotjahn, D. B.; Cooksy, A. L. Computational Study of the Extensive Role of Heterocyclic Ligands in Acetylene Hydration by a Bifunctional Organometallic Catalyst. Organometallics 2013, 32, 6867-6870. (e) Tsou, C.-C.; Yang, W.-L.; Liaw, W.-F. Nitrite Activation to Nitric Oxide via One-fold Protonation of Iron(II)-O,O-Nitrito Complex: Relevance to the Nitrite Reductase Activity of Deoxyhemoglobin and Deoxyhemerythrin. $J$. Am. Chem. Soc. 2013, 135, 18758-18761.

(29) Zaranek, M.; Marciniec, B.; Pawluć, P. Ruthenium-Catalysed hydrosilylation of carbon-carbon multiple bonds. Org. Chem. Front. 2016, 3, 1337-1344.

(30) In general, the outcomes of these hydrosilytation reactions proved difficult to interpret due to the in situ evolution of different catalytically active species. See, for example, reference 20 and: Gao, R.; Pahls, D. R.; Cundary, T. R.; Yi, C. S. Experimental and Computational Studies of the Ruthenium-Catalyzed Hydrosilylation of Alkynes: Mechanistic Insights into the Regio- and Stereoselective Formation of Vinylsilanes. Organometallics 2014, 33, 6937-6944.

(31) (a) Esteruelas, M. A.; Oliván, M.; Oro, L. A. Reactions of the Square-Planar Compounds $\operatorname{Ir}\left(\mathrm{C}_{2} \mathrm{Ph}\right) \mathrm{L}_{2}\left(\mathrm{PCy}_{3}\right)\left(\mathrm{L}_{2}=\mathrm{CO}\right.$, TFB $)$ with $\mathrm{HSiR}_{3}(\mathrm{R}=\mathrm{Et}, \mathrm{Ph})$ and $\mathrm{H}_{\mathrm{x}+1} \mathrm{SiPh}_{3-\mathrm{x}}(\mathrm{x}=1,2)$ : Stoichiometric and Catalytic Formation of $\mathrm{Si}-\mathrm{C}$ Bonds. Organometallics 1996, 15, 814-822. (b) Esteruelas, M. A.; Oliván, M.; Oro, L. A.; Tolosa, J. I. Hydrosilylation of Phenylacetylene Catalyzed by $\left[\operatorname{Ir}(\mathrm{COD})\left(\eta^{2}-i \mathrm{Pr}_{2} \mathrm{PCH}_{2} \mathrm{CH}_{2} \mathrm{OMe}\right)\right]\left[\mathrm{BF}_{4}\right]$. J. Organomet. Chem. 1995, 487, 143-149.

(32) (a) Taylor, J. R. An Introduction to Error Analysis, 2nd ed.; University Science Books: Mill Valley, CA, 1982. (b) Morse, P. M.; Spencer, M. O.; Wilson, S. R.; Girolami, G. S. A Static Agostic $\alpha-\mathrm{CH} \cdots \mathrm{M}$ Interaction Observable by NMR Spectroscopy: Synthesis of the Chromium(II) Alkyl $\left[\mathrm{Cr}_{2}\left(\mathrm{CH}_{2} \mathrm{SiMe}_{3}\right)_{6}\right]_{2}$ and Its Conversion to the Unusual "Windowpane" Bis(metallacycle) Complex $\left[\mathrm{Cr}\left(\kappa^{2}-C, C^{\prime}-\mathrm{CH}_{2} \mathrm{SiMe}_{2} \mathrm{CH}_{2}\right)_{2}\right]_{2}{ }^{-}$. Organometallics 1994, 13, 1646-1655.

(33) Frisch, M. J.; Trucks, G. W.; Schlegel, H. B.; Scuseria, G. E.; Robb, M. A.; Cheeseman, J. R.; Scalmani, G.; Barone, V.; Mennucci, B.; Petersson, G. A.; Nakatsuji, H.; Caricato, M.; Li, X.; Hratchian, H. P.; Izmaylov, A. F.; Bloino, J.; Zheng, G.; Sonnenberg, J. L.; Hada, M.; Ehara, M.; Toyota, K.; Fukuda, R.; Hasegawa, J.; Ishida, M.; Nakajima, T.; Honda, Y.; Kitao, O.; Nakai, H.; Vreven, T.; Peralta, J. E., Jr.; Ogliaro, F.; Bearpark, M.; Heyd, J. J.; Brothers, E.; Kudin, K. N.; Staroverov, V. N.; Kobayashi, R.; Normand, J.; Raghavachari, K.; Rendell, A.; Burant, J. C.; Iyengar, S. S.; Tomasi, J.; Cossi, M.; Rega, N.; Millam, J. M.; Klene, M.; Knox, J. E.; Cross, J. B.; Bakken, V.; Adamo, C.; Jaramillo, J.; Gomperts, R.; Stratmann, R. E.; Yazyev, O.; Austin, A. J.; Cammi, R.; Pomelli, C.; Ochterski, J. W.; Martin, R. L.; Morokuma, K.; Zakrzewski, V. G.; Voth, G. A.; Salvador, P.; Dannenberg, J. J.; Dapprich, S.; Daniels, A. D.; Farkas; Foresman, J. B.; Ortiz, J. V.; Cioslowski, J.; Fox, D. J. Gaussian 09, revision D.01; Gaussian Inc., Wallingford, CT, 2013.

(34) Chai, J. D.; Head-Gordon, M. Long-Range Corrected Hybrid Density Functionals with Damped Atom-Atom Dispersion Corrections. Phys. Chem. Chem. Phys. 2008, 10, 6615-6620. 
(35) Marenich, A. V.; Cramer, C. J.; Truhlar, D. G. Universal Solvation Model Based on Solute Electron Density and on a Continuum Model of the Solvent Defined by the Bulk Dielectric Constant and Atomic Surface Tensions. J. Phys. Chem. B 2009, 113, 6378-6396.

(36) (a) Hehre, W. J.; Ditchfield, R.; Pople, J. A. Self-Consistent Molecular Orbital Methods. XII. Further Extensions of Gaussian-Type Basis Sets for Use in Molecular Orbital Studies of Organic Molecules. J. Chem. Phys. 1972, 56, 2257-2261. (b) Hariharan, P. C.; Pople, J. A. The Influence of Polarization Functions on Molecular Orbital Hydrogenation Energies. Theoret. Chimica Acta 1973, 28, 213-222. (c) Francl, M. M.; Petro, W. J.; Hehre, W. J.; Binkley, J. S.; Gordon, M. S.; DeFrees, D. J.; Pople, J. A. Self-Consistent Molecular Orbital Methods. XXIII. A Polarization-Type Basis Set for Second-Row Elements. $J$. Chem. Phys. 1982, 77, 3654-3665.

(37) (a) Dunning Jr., T. H.; Hay, P. J. Gaussian Basis Sets for Molecular Calculations. In Methods of Electronic Structure Theory; Schaefer III, H. F., Ed.; Modern Theoretical Chemistry, Plenum, New York, 1977; Vol, 3, pp 1-28. (b) Wedig, U.; Dolg, M.; Stoll, H.; Preuss, H. In Quantum Chemistry: The Challenge of Transition Metals and Coordination Chemistry; Veillard, A., Ed.; NATO ASI Series C: Reidel and Dordrecht, 1986; pp 79-89. (c) Fuentealba, P.; Stoll, H.; von Szentpály, L.; Schwerdtfeger, P.; Preuss, H. On the Reliability of SemiEmpirical Pseudopotentials: Simulation of Hartree-Fock and Dirac-Fock Results. J. Phys. B 1983, 16, L323-L28. (d) Bergner, A.; Dolg, M.; Kuechle, W.; Stoll, H.; Preuss, H. Ab Initio Energy-Adjusted Pseudopotentials for Elements of Groups 13-17. Mol. Phys. 1993, 80, 1431-1441.

(38) (a) Krishnan, R.; Binkley, J. S.; Seeger, R.; Pople, J. A. SelfConsistent Molecular Orbital Methods. XX. A Basis Set for Correlated Wave Functions. J. Chem. Phys. 1980, 72, 650-654. (b) McLean, A. D.; Chandler, G. S. Contracted Gaussian Basis Sets for Molecular Calculations. I. Second Row Atoms, Z $=11$ 18. J. Chem. Phys. 1980, 72, 5639-5648.

(39) Harvey, J. N. Ab Initio Transition State Theory for Polar Reactions in Solution. Faraday Discuss. 2010, 145, 487-505.

(40) Besora, M.; Vidossich, P.; Lledós, A.; Ujaque, G.; Maseras, F. On the Calculation of Reaction Free Energies in Solution: A Comparison of Current Approaches. J. Phys. Chem. A 2018, 122, 1392-1399.

(41) Gusev, D. G. Rethinking the Dehydrogenative Amide Synthesis. ACS Catalysis 2017, 7, 6656-6662.

(42) Álvarez-Moreno, M.; de Graaf, C.; López, N.; Maseras, F.; Poblet, J. M.; Bo, C. Managing the Computational Chemistry Big Data Problem: The ioChem-BD Platform. J. Chem. Inf. Model. 2015, 55, 95-103. 